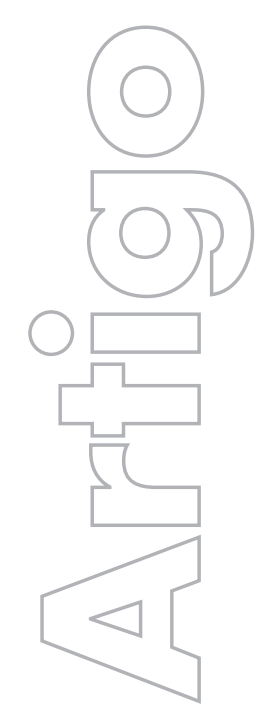

revista

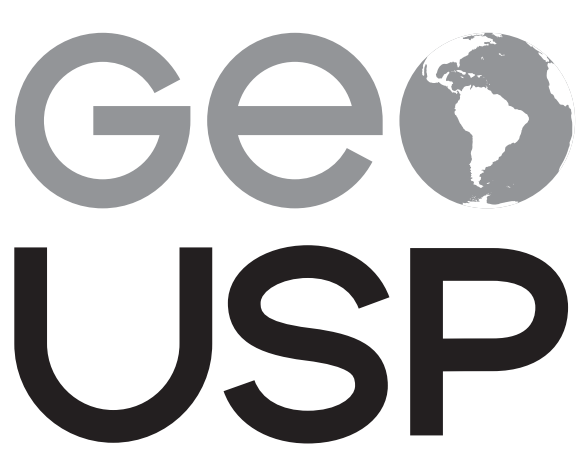

espaço e tempo

Volume $20 \cdot n^{\circ} 1(2016)$

\section{Conflitos socioambientais} na APA de Cairuçu (Paraty-RJ) à luz da sobreposição com unidades de conservação de diferentes categorias

Carine Fonseca Lopes Fontes

UFRJ

Antônio José Teixeira Guerra

UFRJ

p. $178-193$

Como citar:

FONTES, C. F. L.; GUERRA, A. J. T. Conflitos socioambientais na APA de Cairuçu (Paraty-RJ) à luz da sobreposição com unidades de conservação de diferentes categorias. Geousp - Espaço e Tempo (Online), v. 20, n. 1, p. 178-193 mês. 2016. ISSN 2179-0892.

Disponível em: http://www.revistas.usp.br/geousp/article/ view/85275. DOI: http://dx.doi.org/10.11606/issn.21790892.geousp.2016.85275.

\section{(c) $(1)(9)$}

Este artigo está licenciado sob a Creative Commons Attribution 4.0 License. 


\section{Conflitos socioambientais na APA de Cairuçu (Paraty-RJ) à luz da sobreposição com unidades de conservação de diferentes categorias ${ }^{1}$}

\section{Resumo}

A APA de Cairuçu, Paraty-RJ constitui-se num corredor ecológico entre diversas unidades de conservação (UC) do estado. Este trabalho busca identificar os conflitos socioambientais da APA para analisá-los à luz da sobreposição com outras UC e discuti-los do ponto de vista de gestão e manejo. Para tanto, fizeram-se levantamento bibliográfico e extensos diálogos sociais em trabalhos de campo. Como resultado, observaram-se na UC numerosos conflitos com em sua própria gênese, o zoneamento proposto pelo Plano de Manejo acirra os conflitos existentes, sobretudo na porção insular da APA, e que há conflitos no território relativos à sobreposição de diversos instrumentos de planejamento e gestão com duplicidade de regramentos.

Palavras-chave: Conflitos socioambientais. Unidades de conservação. Gestão. Manejo. Populações tradicionais.

\section{Socio-environmental conflicts in Cairuçu} Environmental Protection Area (APA), Paraty Municipality, under the view of Conservation Units overlay of different categories

\section{Abstract}

Cairuçu Protection Area is an ecological corridor, linking several Conservation Units in Rio de Janeiro State. This article aims to identity the socioenvironmental conflicts within the Protetion Area, and to analyze them taking into account the overlay with other Conservation Units, under its management. In order to reach that, we have carried out bibliographic survery

Os autores agradecem o apoio da Fundação de Amparo à Pesquisa do Estado do Rio de Janeiro (FAPERJ) e do Conselho Nacional de Desenvolvimento Científico e Tecnológico (CNPq), importantes órgãos de fomento à realização de pesquisas, pela realização desse artigo. 
and social dialogues, during field work. As a result we have observed a great number of conflicts within the Conservation Unit, whose origin is related to its own birth; the proposed zoning by the Management Plan enhances the existing conflicts, including the islands inside the Protetion Area; and there are conflicts related to the overlay of several instruments of planning and management with different rules.

Keywords: Socio-environmental conflicts. Conservation units. Management. Manejo. Traditional populations.

\section{Introdução}

Nas últimas décadas do século XX, a questão ambiental ganhou destaque em todo o mundo, a partir da necessidade de conservação e preservação dos ecossistemas (Castro Jr.; Coutinho; Freitas, 2009). No âmbito nacional, a situação das unidades de conservação (UC) no Brasil é bastante precária, pois, além de pouco representativas em relação ao tamanho do país, muitas não foram efetivamente implantadas nem estruturadas adequadamente (Dios, 2005).

Atualmente, multiplicaram-se o número e os tipos de estudos geográficos sobre unidades de proteção ambiental criadas no território brasileiro pelos poderes públicos federal, estadual e municipal, visto que, o nosso Sistema Nacional de Unidades de Conservação (Snuc) representa um alicerce ainda frágil para suportar as pressões sobre a biodiversidade e necessita de estudos significativos. Portanto, é nesse contexto que surgiu a necessidade de se trabalhar com uma UC de uso sustentável gerida pelo Instituto Chico Mendes de Conservação da Biodiversidade (ICMBio), denominada área de proteção ambiental (APA) de Cairuçu.

Inserida na região na baía da Ilha Grande (BIG), estado do Rio de Janeiro, município de Paraty, litoral sul fluminense, a área de estudo insere-se na reserva da biosfera da Mata Atlântica, estabelecida pelo Decreto no 26.057/2000, e faz parte da Mata Atlântica brasileira, bioma que historicamente vem sendo degradado.

A APA (Figura 1) une fragmentos importantes desse bioma, constituindo-se num grande corredor ecológico, interligando UC do litoral norte paulista, ao sul fluminense; está sobreposta a outras UC de diferentes categorias de manejo; permite diversos usos e atividades econômicas; sua proximidade com o mar faz com que a unidade sofra pressões ligadas ao turismo; e concentra um significativo contingente populacional, incluindo comunidades tradicionais.

A UC ocupa cerca de 40\% do município de Paraty e, por ser composta por uma extensa área, que engloba tanto o território continental quanto o insular, há muitos conflitos inerentes a sua presença na região. Se sobrepõe, parcialmente, ao Parque Nacional 
da Serra da Bocaina (PNSB) (Figura 1) e, integralmente, a Reserva Ecológica Estadual da Juatinga (REJ) (Figura 1). Na parte marinha há sobreposição com a APA da Baía de Paraty, Enseada de Paraty-Mirim e Saco do Mamanguá (Figura 1), pelo que assegura o seu Plano de Manejo.

Se, por um lado, podem ser consideradas indicadores da diversidade e relevância ambiental da área, por outro, por envolver instituições das três esferas - federal, estadual e municipal -, essas sobreposições criam grandes conflitos socioambientais e, consequentemente, enormes dificuldades em termos de gestão desse território, pois as competências entre os diferentes órgãos muitas vezes se justapõem, devendo ser geridas com responsabilidades muito claras.

Segundo D. Brito (2008) e M. Brito (2003), os conflitos em UC constituem uma realidade que vem sendo construída desde a instituição das primeiras áreas protegidas. Compreendê-los é importante para a formulação das políticas e diretrizes que envolvem a construção da gestão e do manejo das UC, pois, em ultima análise, os conflitos refletem o processo histórico das lutas sociais e da transformação econômica na construção dos espaços geográficos. Segundo Theodoro (2005), os conflitos são partes integrantes das relações humanas, da trama social, são tão diversos quanto as relações sociais.

Nessa proposta, Little (2006) caracteriza o conflito socioambiental como um embate entre grupos sociais que decorre de suas diferentes formas de inter-relacionamento com seu meio social e natural. Para Vivacqua e Vieira (2005), conflito socioambiental designa as relações sociais de disputa/tensão entre diferentes grupos, ou atores sociais pela apropriação e gestão do patrimônio natural e cultural. Se expressa nos interesses e usos do espaço e recursos naturais pelas populações locais e os interesses e usos possíveis, segundo os objetivos de conservação (Vianna, 2008; Vianna; Adams; Diegues, 1994).

No caso específico da APA de Cairuçu, tal interesse tende acirrar-se pelo fato de um mesmo território estar permeado por múltiplos atores e instituições que o gerenciam, norteados pela categoria de manejo na qual cada UC está inserida. Estudar os conflitos é dar visibilidade no debate aos distintos atores sociais que resistem aos processos de monopolização dos recursos ambientais nas mãos dos grandes interesses econômicos (Acselrad, 2004).

Nesse sentido, este trabalho busca identificar os conflitos socioambientais existentes na APA de Cairuçu, analisá-los à luz da sobreposição com UC de diferentes categorias de manejo e discutir os aspectos de gestão de uma unidade cujo território está sobreposto a outras áreas protegidas. Para tanto, busca-se realizar um diagnóstico da efetividade do zoneamento proposto pelo Plano de Manejo da APA e espacializar os principais conflitos existentes, contribuindo para o planejamento ambiental da UC, fornecendo subsídios à gestão do território. 


\section{Figura 1 - Mapa da APA de Cairuçu e demais UC que se sobrepõem ao território}

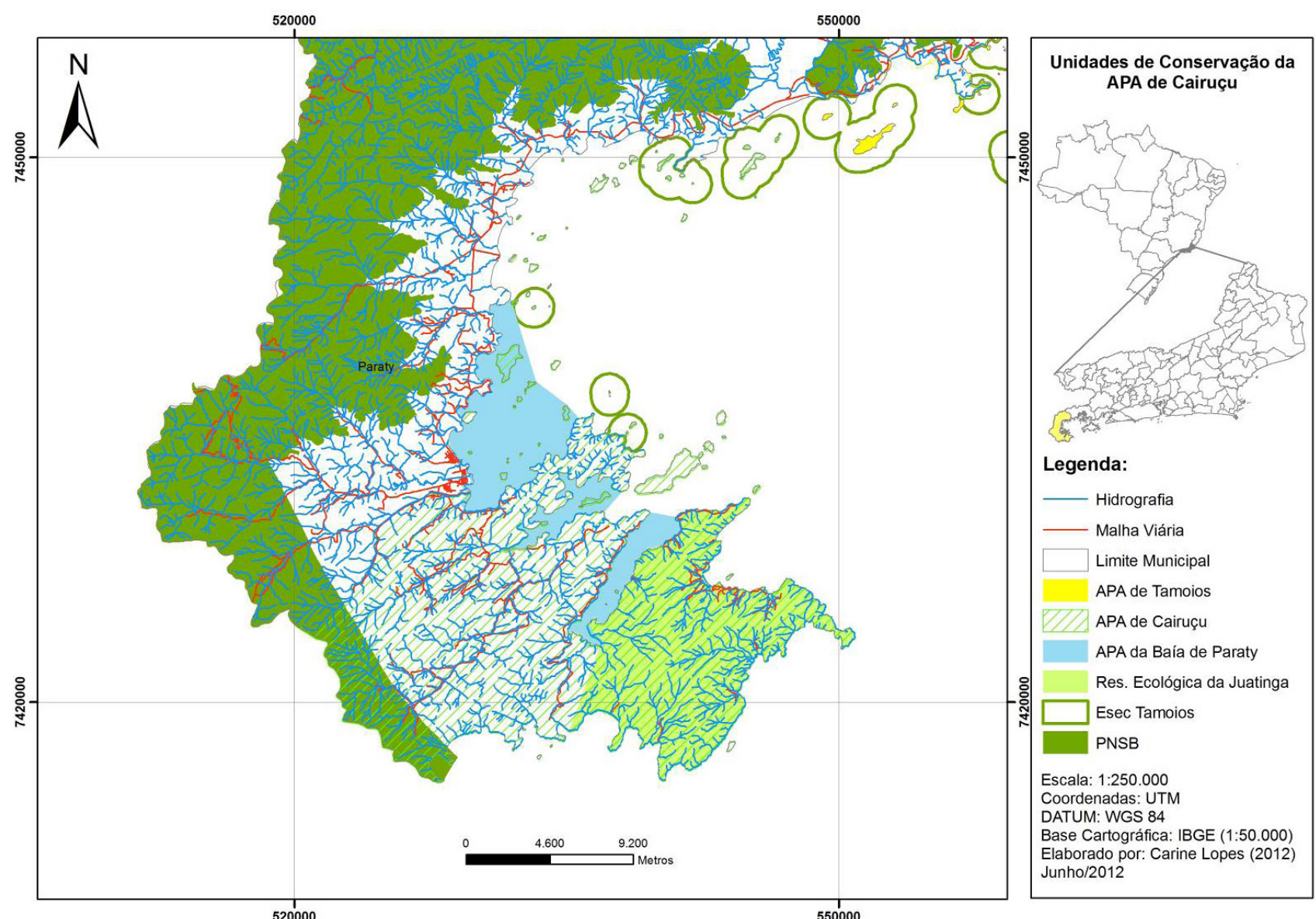

fonte: Carine Fonseca Lopes Fontes e Antônio José Teixeira Guerra, 2013.

\section{Materiais e métodos}

Para o alcance dos objetivos propostos, primeiramente, se recorreu a levantamentos bibliográficos diversos acerca do tema, incluindo consultas a publicações da área, ao Plano de Manejo da APA de Cairuçu e das demais UC sobrepostas, as atas das reuniões dos Conselhos das UC que compõem o mosaico, a livros, artigos acadêmicos, periódicos, dissertações e teses, além de sites oficiais e legislações diversas.

Paralelamente, para obtenção de dados primários, trabalhos de campo foram de suma importância para a pesquisa. Eles possibilitaram: coletar dados locais; dialogar, por meio de entrevistas, com diversos atores sociais que atuam no território em questão, especificamente, gestores de UC, instituições governamentais estratégicas e representantes da sociedade civil; e participar de reuniões de colegiados gestores.

A partir da identificação dos principais atores sociais foi elaborado um roteiro para as entrevistas. Optou-se pela metodologia de entrevistas semiestruturadas, para todos os entrevistados e o resultado das mesmas permitiu uma análise subjetiva dos discursos proferidos. Para Manzini (2004), entrevista semiestruturada está focalizada em um assunto sobre o qual confeccionamos um roteiro com perguntas principais, complementadas por outras questões inerentes às circunstâncias momentâneas da entrevista. 
Considerando a grande variabilidade dos atores sociais que atuam na APA, foi necessária uma seleção prévia do grupo, que abarcou: gestor e analistas ambientais da APA de Cairuçu (ICMBio); gestor da Reserva Ecológica Estadual da Juatinga (Inea); analistas ambientais que gerenciam as UC da Baía da Ilha Grande (BIG) do Instituto Estadual do Ambiente (Inea); Analistas da Superintendência da Baía da Ilha Grande (Supbig); técnicos e secretários da Prefeitura Municipal de Paraty, mais especificamente: Secretaria de Desenvolvimento Urbano e Meio Ambiente (Seduma), Secretaria de Pesca e Agricultura e Secretaria de Turismo, além de e representantes da sociedade civil e UC sobrepostas.

$\bigcirc$ intuito das entrevistas foi identificar os conflitos socioambientais existentes no território em questão; compreender a gestão do território como um todo, pois na prática está compartilhada e fragmentada entre diversos atores e esferas de competências; diagnosticar a efetividade do zoneamento proposto pelo Plano de Manejo da APA e os conflitos entre esses e as populações tradicionais caiçaras.

Concomitantemente, para compreender a dinâmica local e os problemas vivenciados no território, foi fundamental participar de diversas reuniões de colegiados gestores locais, especificamente: Conselho Consultivo da APA (Conapa) Cairuçu; Grupo Técnico (GT) de Monitoramento e Fiscalização da Baía da llha Grande (BIG) e Conselho Consultivo do Mosaico Bocaina.

As discussões a partir das reuniões do Conapa foram fundamentais, pois permitiram compreender mais claramente os principais problemas vivenciados na escala local da UC, assim como identificar os principais conflitos e atores. Igualmente, a participação nas reuniões do GT de Monitoramento e Fiscalização da BIG revelou-se estratégica por envolver instituições fiscalizadoras dos municípios de Angra dos Reis, Paraty e Mangaratiba, com ações voltadas ao planejamento e ao monitoramento da baía. Por fim, a participação nas reuniões do Mosaico Bocaina, por reunir um grupo heterogêneo, formado por UC das três esferas do poder público, permitiu compreender o problema numa escala regional.

\section{Resultados e discussão}

A APA de Cairuçu ocupa quase a metade do município de Paraty (40\%) e, por ser composta por uma área extensa, que engloba tanto o território continental quanto o insular do município, há muitos conflitos inerentes a sua presença na região. Na porção continental, a sobreposição da APA com outras UC de diferentes categorias de manejo, cujos usos são mais restritivos, cria diversos conflitos em termos de gestão no território. Na parte marinha, igualmente, há conflitos entre os atores.

\section{Sobreposição da APA de Cairuçu com a APA Marinha da Baía de Paraty, a Enseada de Paraty-Mirim e o Saco do Mamanguá}

A APA Marinha da Baía de Paraty, Enseada de Paraty-Mirim e Saco do Mamanguá (Figura 1), UC de Uso Sustentável localizada em Paraty - RJ, que abarca as áreas abrigadas da APA de Cairuçu, cuja gestão está sob a responsabilidade da Secretaria de Desenvolvimento Urbano e Meio Ambiente (Seduma) da Prefeitura de Paraty, é uma das 
unidades estrategicamente importantes para a gestão da APA: socialmente, representa uma ótima opção de lazer e de desenvolvimento cultural para a população; ambientalmente, por abarcar manguezais e estuários em sua extensão, tem relevância para a manutenção da qualidade ambiental da região e; economicamente, além da presença do turismo aquático, gera possibilidade de subsistência a diversas comunidades caiçaras que realizam a pesca artesanal neste local.

Conforme apontado por Benchimol (2007), criada um ano antes da APA Marinha da Baía de Paraty, Enseada de Paraty-Mirim e Saco do Mamanguá, a APA de Cairuçu inclui toda a região dessa UC, com exceção de seu corpo hídrico. Ou seja, há uma interseção na área insular. É intrigante pensar no porquê de se criar uma UC que proteja o continente e as ilhas, e, um ano após, criar-se outra área protegida abrangendo o corpo hídrico. Crê-se que a criação da APA, para o governo municipal, pôs em pauta a importância de se preservar o meio ambiente através de UC, incentivando a posterior criação da APA da Baía de Paraty.

Ao observar as duas leis de criação da APA Marinha (Paraty, 1984, 1987), contraditoriamente, percebe-se que não é clara a delimitação de sua área de abrangência. Porém, analisando interpretativamente ambas as leis, é impossível inferir seus limites descontínuos (Figura 1).

Além da falta de clareza quanto à delimitação dessa área, observa-se uma falta de esclarecimento legal quanto ao próprio nome da unidade em tela, ora chamada APA da Baía de Paraty, conforme o texto legal de criação, ora chamada APA Marinha da Baía de Paraty, Enseada de Paraty-Mirim e Saco do Mamanguá, conforme a lei que amplia seus limites.

Deixando de lado esse problema, outra questão relevante que merece ser destacada na discussão é o próprio texto legal de criação da unidade (Paraty, 1984), em cujos artigos $4^{\circ}$ e $5^{\circ}$ se observa antecipadamente o estabelecimento de alguns usos proibidos no território marinho, proibição essa imposta de "cima para baixo", sem uma gestão compartilhada/participativa com a sociedade civil:

Art. 40 - Fica proibida a extração e pesca de mariscos e camarões ou de quaisquer moluscos para fins comerciais dentro desta Área de Proteção Ambiental sendo autorizada somente a coleta para o próprio sustento das populações vizinhas (dentro de padrões criteriosos de extração).

Art. 50 - Nesta Área de Proteção Ambiental fica proibido: a) a implantação e o funcionamento de indústrias potencialmente poluidoras; b) a realização de obras de terraplanagem e a abertura de canais; c) o exercício de atividades capazes de provocar acelerada erosão das terras, ou acentuado assoreamento dos rios, dos mangues ou do mar; d) o exercício de atividades que ameacem extinguir nesta área protegida as espécies raras da biota regional.

Além da proibição de extração e pesca de mariscos, camarões ou quaisquer moluscos para fins comerciais dentro da APA, essa mesma área tornou-se "área de proibição permanente à pesca" (Mapa, 1987), ficando proibida a pesca de arrasto pelo sistema de portas e parelhas. Porém, conforme aponta Breton (2005), mesmo com a criação de uma zona protegida na baía de Paraty, as autoridades nunca tiveram os meios de frear as incursões frequentes dos pescadores artesanais em barcos de alto-mar. 
Na atualidade, com a política do Snuc e seu direcionamento legal para uma gestão democrática e participativa, cabe ao Plano de Manejo da UC criar tais restrições. E, embora, na prática, a gestão das unidades esteja longe de um consenso entre os atores envolvidos, além do fato de muitas ainda carecerem de recursos financeiros para propor seus Planos, há uma orientação para que as restrições não sejam impostas arbitrariamente nos textos legais de criação. Ao contrário, que se dê com a participação efetiva da sociedade, sobretudo no território de uma APA, que por si só, admite diversos usos.

Porém, e com intuito de relativizar a importância dada aos Planos de Manejo das UC, supervalorizados pelos órgãos gestores, conforme afirma Pádua (2011), com ou sem Planos de Manejo, as autoridades têm de manejar suas UC. Endeusá-los virou moda, como se eles próprios por si só pudessem, com uma vara de condão, resolver os problemas do dia a dia de gerente de uma UC.

Portanto, embora existam marcos regulatórios para o uso do espelho d’água na APA da Baía de Paraty, na prática, foi constatado por meio das entrevistas com a Seduma, gestora da unidade, e Secretaria de Pesca da Prefeitura de Paraty, responsável pela fiscalização da atividade, que não há uma gestão efetiva na UC, pois a APA existe apenas no papel, sendo desconhecida pela própria população local. Parte pela falta de infraestrutura das secretarias, que ainda estão em fase de organização interna. Parte porque, historicamente, a unidade foi totalmente esquecida pelo órgão gestor.

Tornando a questão mais complexa, parte da área de abrangência dessa APA Marinha, especificamente o Saco do Mamanguá, foi contemplada no Plano de Manejo da APA de Cairuçu - instituído pela Portaria do Ibama n. 28, de 28 de abril de 2005. Porém, segundo o decreto de criação da APA de Cairuçu (Decreto n. 89.242/1983, Art. $2^{\circ}$ ), ela é composta apenas por duas partes: uma continental e outra insular, não abarcando, portanto, o espelho d’água. Assim, ao propor uma zona de conservação dos recursos pesqueiros para a região do Mamanguá, o Plano de Manejo cria um impasse legal com relação ao próprio decreto de criação da APA.

A zona de conservação dos recursos pesqueiros, subdividida pelo Plano de Manejo da APA de Cairuçu em quatro subzonas (de Santuário Marinho; de Proteção do Santuário; de Reserva de Pesca Artesanal e de Proteção Ambiental), visa estabelecer níveis diferenciados de conservação e proteção nos ambientes marinhos do Saco do Mamanguá, com maiores restrições ao fundo, e menores, na área mais externa do Mamanguá. Para tanto, o zoneamento nessas quatro subzonas, em comum, proibiu a pesca de arrasto, incluindo a pesca de arrasto de fundo, e permitiu a pesca artesanal, dentro das especificações legais quanto ao tamanho da malha e a períodos de defeso ou respeito à época de reprodução da espécie capturada.

Embora esse zoneamento tenha se orientado nas leis de criação da APA da Baía de Paraty, assim como na Portaria n. 03-N (Mapa, 1987), na prática, fiscalizar a pesca de arrasto e artesanal dentro das especificações legais quanto ao tamanho da malha e períodos de defeso é muito complicada, pois a Prefeitura carece de recursos financeiros e técnicos. E, mesmo que - Plano da APA de Cairuçu também tenha criado restrições, não cabe ao seu órgão gestor (ICMBio) fiscalizar esse corpo hídrico. Portanto entre o que está proposto no Plano e sua prática efetiva, há um longo distanciamento. 
No âmbito da prefeitura, observa-se que além da falta de recursos financeiros e de prioridade política para gestão da UC, há pouca comunicação interna entre as próprias secretarias, o que dificulta uma fiscalização adequada. Por meio de entrevistas, a Secretaria de Pesca nos informou que realiza, através de embarcação alugada, uma modesta fiscalização quanto ao descumprimento do defeso do camarão e caranguejo, pesca de arrasto e pesca ilegal nos manguezais ao fundo do Mamanguá, mas, para ser mais eficiente, necessita do apoio de outros órgãos, para que a ação seja pensada e planejada numa escala mais ampla.

\section{Sobreposição com a Reserva Ecológica Estadual da Juatinga}

Com 9.797 ha sobrepostos à APA de Cairuçu (equivalente a 30,6\%) e localizada no extremo sul do estado do Rio de Janeiro, em Paraty, a REJ (Figura 1) foi criada pelo Decreto Estadual n. 17.981, de 30 de outubro de 1992. De natureza non edificandi, tem o objetivo de preservar o ecossistema, composto por costões rochosos, remanescentes florestais de Mata Atlântica, restingas e mangues, que, em conjunto com o mar, forma um cenário de notável beleza.

Administrada a princípio pelo Instituto Estadual de Florestas do Rio de Janeiro (IEF-RJ), atual Instituto Estadual do Ambiente (Inea), a unidade abriga doze núcleos de populações tradicionais, que se distribuem ao longo do litoral, vivendo da pesca artesanal, agricultura de subsistência e, mais recentemente, do turismo. Os núcleos se relacionam entre si e usam a cidade de Paraty como centro de comércio e serviço, apesar da precariedade de acesso - a pé, por trilhas, ou barcos.

No período pós-construção da rodovia Rio-Santos (BR-101), na década de 1970, que veio acompanhada do turismo e da forte especulação imobiliária, vários conflitos fundiários se intensificaram na região. Esses conflitos foram precursores da criação da REJ, em 1992. Uma vez criada, a REJ teve como objetivo a preservação dos remanescentes da Mata Atlântica e a manutenção das comunidades tradicionais caiçaras.

Segundo Diegues (2001, 2004), caiçaras são grupos humanos diferenciados, formados pela mescla da contribuição étnico-cultural dos indígenas, colonizadores portugueses e, em menor grau, escravos africanos. Caracterizadas por uma cultura específica que se desenvolveu principalmente nas áreas costeiras dos estados do Rio de Janeiro à Santa Catarina. Apresentam um estilo de vida baseado em atividades de pesca artesanal, agricultura, extrativismo, artesanato, caça e, mais recentemente, construção civil e turismo (Adams, 2000).

Embora criada com esse intuito - preservação da Mata Atlântica e a manutenção das comunidades caiçaras -, a REJ convive historicamente com sérios conflitos fundiários, sobretudo entre grileiros e caiçaras. Em entrevista com um morador da Praia do Sono, foi informado que, desde a década de 1990, essa praia é palco de um conflito histórico entre o grileiro Gibrail Tannus e os caiçaras locais. Segundo ele, embora esse problema tenha diminuído nos dias atuais, a especulação fundiária e a venda de posses para pessoas "de fora" ainda é muito recorrente. 
Além disso, a incerteza quanto à possibilidade de permanência da população em seu local de origem é outro entrave relatado por moradores locais, que acaba acirrando suas relações com o órgão ambiental gestor. Segundo Benchimol (2007), a REJ é um típico exemplo de UC criada de "cima para baixo". Nota-se claramente que, mesmo tendo sido criada em prol da cultura caiçara, a população não foi consultada antes de sua criação e até hoje desconhece seus reais direitos.

A denominação reserva ecológica tem causado muita polêmica e dificuldade na aplicação da lei no interior da REJ, afinal, sua categoria não é reconhecida pelo Snuc (Brasil, 2000). Desde a sua criação, as condições de implantação e gestão sofrem restrições de recursos financeiros e humanos, dificultando as atividades de fiscalização. Segundo Artigo 55 do Snuc, as UC criadas com base em legislações anteriores, não pertencentes às categorias previstas, devem ser reavaliadas no todo ou em parte no prazo de dois anos, a partir de 2000, com vistas à adequação.

Através de entrevista com a Gerência de Unidades de Conservação de Proteção Integral (Gepro)/Inea, responsável pela gestão de UC de Proteção Integral, "embora a REJ não pertença a nenhuma das categorias estabelecidas no Snuc, na prática, sempre foi gerida como UC de Proteção Integral." E, "mesmo que, a rigor, as unidades que pertencem a tal grupo devam estar livres da ação humana e da utilização dos recursos naturais, como o decreto de criação da REJ prevê fomento à cultura caiçara, o órgão gestor vem tentando estabelecer um diálogo mais estreito com a população". Contudo, ressaltaram que "ainda há atritos entre as partes, fruto de um histórico processo de gestão autoritária do antigo órgão (IEF), na qual a população se sentia coibida e ameaçada, sem garantia dos seus direitos".

Em 2011, numa tentativa de minimizar a questão, e pela própria necessidade de adequação da unidade à política do Snuc, o Inea contratou um estudo para a recategorização da REJ. Ele está sendo avaliado internamente e, de modo geral, há proposta que parte do território seja transformado em parque, parte, em reserva de desenvolvimento sustentável (RDS), existindo, algumas áreas de forte especulação fundiária indefinidas (Igara Consultoria em Aquicultura e Gestão Ambiental, 2011).

Especificamente para o Mamanguá, ainda há indefinição se a área ocupada pelas três comunidades tradicionais será transformada em RDS ou mantida como APA, já que a área se sobrepõe a APA de Cairuçu. Essa recategorização deve considerar muito claramente o que se deseja para o território da REJ, em termos de utilização e uso dos recursos, assim como que grupo se deseja manter e preservar. Espera-se que, na prática, tal proposta legitime o direito da população tradicional de permanecer em seu local de origem, assegurando seus direitos.

A REJ, mesmo 21 anos depois de criada, ainda carece de um Plano de Manejo próprio. Segundo a Gepro, a Fundação SOS Mata Atlântica já tentou elaborar um Plano para a área. Porém, a proposta não foi aprovada pelo órgão gestor da época (IEF) em função de o zoneamento da $\mathrm{N}$ G não estar alinhado aos interesses da instituição gestora. Segundo eles, outra 
tentativa frustrada foi a da própria instituição implantar um regulamento interno para a REJ, pois, como a unidade carecia de um texto jurídico, esse instrumento tentaria sanar tal carência, mas, infelizmente, por questões políticas, isso não ocorreu.

Ainda quanto ao Plano de Manejo da REJ, existe uma questão curiosa que merece ser ressaltada. Embora os gestores da REJ não tenham aceitado a ingerência da Fundação SOS Mata Atlântica na elaboração desse instrumento para a unidade, contraditoriamente, ao elaborar o Plano de Manejo da APA de Cairuçu, a mesma ONG acabou delimitando para a REJ um zoneamento em função da sobreposição entre ambas. Isso acabou gerando certo desconforto entre o Ibama, antigo gestor da APA (atual ICMBio) e o IEF, antigo órgão e gestor da REJ (atual Inea), levando a um parcial descrédito quanto ao estabelecido no Plano da APA.

Segundo o gestor da APA de Cairuçu, o Plano de Manejo da UC foi feito para a Juatinga também e o zoneamento proposto é utilizado como referência até hoje pelo órgão gestor da REJ. Porém, conforme informado pelo gestor da Reserva, embora esse Plano seja utilizado para embasar os pareceres emitidos pela unidade, na prática, seu zoneamento não é totalmente aceito pelo órgão administrador, em função da flexibilidade do instrumento, cujas zonas estão alinhadas aos interesses de uma APA.

Analisando o Plano de Manejo da APA, as seguintes zonas foram propostas para o território da REJ: Zona de Preservação da Vida Silvestre (ZPVS), Zona de Conservação Costeira (ZCC), Zona de Uso Comunitário, Cultural, Educacional, Esporte e Lazer (Zucel) e Zona de Expansão das Vilas Caiçaras (ZEVC). Essas, em conjunto, admitem alguns usos para a área, já que foram propostas para o território de uma APA, contraditório com os interesses de uma REJ e, de forma muito peculiar, chegam a ter zonas específicas para o território da reserva. Portanto, praticamente estamos falando de dois Planos: um com zonas propostas para o território da APA, outro com zonas específicas para o território da REJ, o tem gerado certo descrédito e ilegitimidade por parte do órgão administrados e gestor da REJ quanto ao disposto no Plano.

Uma solução apontada pelo Inea, que poderia ter dado maior legitimidade a esse zoneamento da APA, teria sido a delimitação de uma única zona para toda a área da REJ - a Zona de Preservação da Vida Silvestre (ZPVS) -, como foi feito na área da APA sobreposta ao PNSB, que, impondo usos bem restritivos, permitiria que o órgão ambiental estabelecesse seus critérios no território em questão.

Outro problema apontado no Plano de Manejo da APA, segundo o gestor da REJ, está especificamente na ZEVC, pois, como o próprio nome - "expansão" - sugere, esse zoneamento não delimitou apenas o perímetro onde residiam as populações caiçaras da REJ. Ao contrário, se delimitou uma área maior que a ocupação da população, prevendo seu crescimento. Segundo ele, "isso é contraditório, pois, como a reserva é de natureza "não edificante", o órgão gestor, teoricamente, não aceita a construção, ou o estabelecimento de novas edificações após 92, ano de criação da UC, mesmo que essas novas residências sejam de agrupamentos tradicionais. A instituição autoriza apenas obras de reforma, desde que sem ampliação. Esse, portanto, representa hoje o principal ponto de conflito na REJ." 


\section{Sobreposição com o Parque Nacional da Serra da Bocaina}

Com 3.807 ha de área sobreposta à APA de Cairuçu (equivalente a 11,9\%) e situado em sua porção mais alta, no extremo leste, o PNSB (Figura 1) é uma das maiores áreas de Mata Atlântica protegidas do país. Fica num trecho da Serra do Mar, na divisa entre os estados do Rio de Janeiro e de São Paulo, e é circundado por importantes núcleos populacionais.

Foi criado pelo Decreto Federal n. 68.172, de 4 de fevereiro de 1971, sob jurisdição do extinto Instituto Brasileiro de Desenvolvimento Florestal (IBDF), sendo a primeira unidade de proteção integral do município de Paraty, na ocasião com 134.000 ha. Um ano mais tarde, em detrimento de um novo Decreto Federal n. 70.694, de 8 de junho de 1972, a área do parque foi reduzida para 104.000 ha, tendo havido uma perda significativa de 30.000 ha.

Especula-se que sua criação esteve atrelada a um momento de forte pressão quanto à especulação imobiliária e aos grandes projetos de ocupação turística e hoteleira no município. Seus limites, de antemão, já demonstravam a força dos grandes empreendimentos locais, com a exclusão da área onde hoje se situa o Condomínio Laranjeiras da área do futuro parque. Segundo Breton (2005), os limites do parque foram modificados em certos lugares e momentos para acomodar os empresários privados, agrários ou turísticos, sendo acompanhado de desapropriação de numerosos posseiros pelo uso da força, ocasionando diversos conflitos.

Mesmo com a criação dessa unidade, a faixa litorânea ainda estava bastante vulnerável, o que levou o governo federal criar a APA de Cairuçu, em 1983. A APA, no entanto, como uma categoria de manejo mais flexível que admite diversos usos, abarcando desde a proteção do ambiente natural, paisagens de grande beleza e sistemas hidrológicos, por fomentar a proteção às comunidades caiçaras integradas nesse ecossistema, poderia ser uma válvula de escape para os conflitos com as comunidades nas áreas sobrepostas. Mas, infelizmente, na prática, a proposição da APA não solucionou tais problemas.

Segundo entrevista com o gestor da APA de Cairuçu, como nas áreas sobrepostas por outras UC à gestão de cada uma é autônoma e independente, prevalecendo às regras mais restritivas, a criação da APA não poderia contribuir para flexibilizar a problemática das áreas sobrepostas ao parque. Além disso, como o PNSB tem seu próprio Plano de Manejo, concluído em 2001 e aprovado em 2002, com propostas de zoneamento e normas individualizadas, que levam em consideração graus específicos de proteção, a sua gestão se configura mais autônoma que as demais UC sobrepostas, não havendo tanta interlocução entre ambas.

Analisando o zoneamento proposto no Encarte VI (Planejamento) do Plano de Manejo do parque (2001), que tem como prerrogativa ser um instrumento técnico de gestão voltado à preservação e máxima conservação dos recursos naturais, das sete zonas propostas para seu território, cinco se sobrepõem à APA de Cairuçu: Zona Primitiva, Zona de Recuperação, Zona de Uso Extensivo, Zona de Uso Intensivo e Zona de Uso Especial. Tais zonas felizmente não apresentam conflitos de sobreposição com as propostas para a APA, pois, por se tratar de uma UC de Proteção Integral, toda a área da APA sobreposta foi classificada como 
Zona de Preservação da Vida Silvestre (ZPVS), cujo uso é bem restritivo. Assim, se evitou não apenas uma duplicidade de regras entre os dois instrumentos, como conflitos na gestão do uso de um mesmo território.

Uma questão curiosa que se observa na gestão de ambas, porém, é que, mesmo se tratando de UC da mesma esfera de governo - Federal -, geridas, pelo mesmo órgão - ICMBio -, que dividem, inclusive, o mesmo espaço em termos de administração, não há uma gestão compartilhada entre os seus administradores, contrariando a recomendação do Ministério do Meio Ambiente (MMA) e a lógica do próprio Sistema Nacional de Meio Ambiente (Sisnama), em que os órgãos ambientais devem conduzir a gestão das UC de compartilhada e participativamente.

\section{Espacialização dos conflitos na APA de Cairuçu}

Como previamente discutido, há muitos conflitos no território da APA de Cairuçu. Se, por um lado, a sobreposição dessa unidade com outras áreas protegidas the confere um caráter muito singular, por outro, a grande variedade dos conflitos está muito ligada à própria natureza e à singularidade de cada unidade que se sobrepõe.

No âmbito do PNSB, categoria de Proteção Integral, segundo o Snuc, os principais conflitos presentes no território sobreposto à APA estão atrelados à entrada de palmiteiros e caçadores; a desmatamentos para uso agropecuário de subsistência; a queimadas; ao turismo intensivo sem controle ou monitoramento adequado ao longo das estradas e trilhas, associado à presença de motoqueiros, jipeiros e mochileiros; à população residente esparsa, com intensa rede de vias de acesso e deslocamentos; e à ocupação desordenada junto à praia de Trindade (Figura 2).

No âmbito da Reserva Ecológica Estadual da Juatinga (REJ), unidade de conservação gerida como pertencente ao grupo de Proteção Integral, há conflitos de diversas ordens e escalas, mas o principal é relativo à questão fundiária, sobretudo na Praia do Sono, no Pouso da Cajaiba e em Martin de Sá. Nas duas primeiras, a área tem sido foco de conflitos fundiários entre a família Gibrail Tannus e os caiçaras da localidade, e, em Martin de Sá, entre os caiçaras e a família Pacheco. Além disso, a especulação fundiária e a venda de posses de pessoas da própria comunidade ainda representam entraves à região, associados à grande expansão de casas de segunda residência, especialmente no Mamanguá (Figura 2).

No âmbito da APA de Cairuçu, na área continental, há conflitos fortemente ligados à extração irregular de minerais às margens de corpos hídricos; expansão urbana desordenada; loteamentos irregulares nas áreas rurais e urbanas; poluição de corpos hídricos; desmatamentos; ocupação em área de preservação permanente (APP); e, ausência de políticas de saneamento. Enquanto nas áreas insulares e costeiras há grande interferência construtiva sobre a paisagem, praia e costão rochoso; atividades turísticas e comerciais desordenadas; bares na faixa de praia; privatização de espaço público; uso e ocupação em desacordo as legislações; forte especulação imobiliária; interesses individuais de propriedade; exploração exacerbada dos recursos naturais; loteamento, parcelamento e venda de lotes de forma irregular; carência quanto à regularização fundiária; e ausência de políticas públicas de saneamento (Figura 2). 


\section{Figura 2 - Mapa croqui dos conflitos socioambientais presentes no território da APA de Cairuçu, com destaque dos conflitos nas UC que se sobrepõem à APA de Cairuçu}

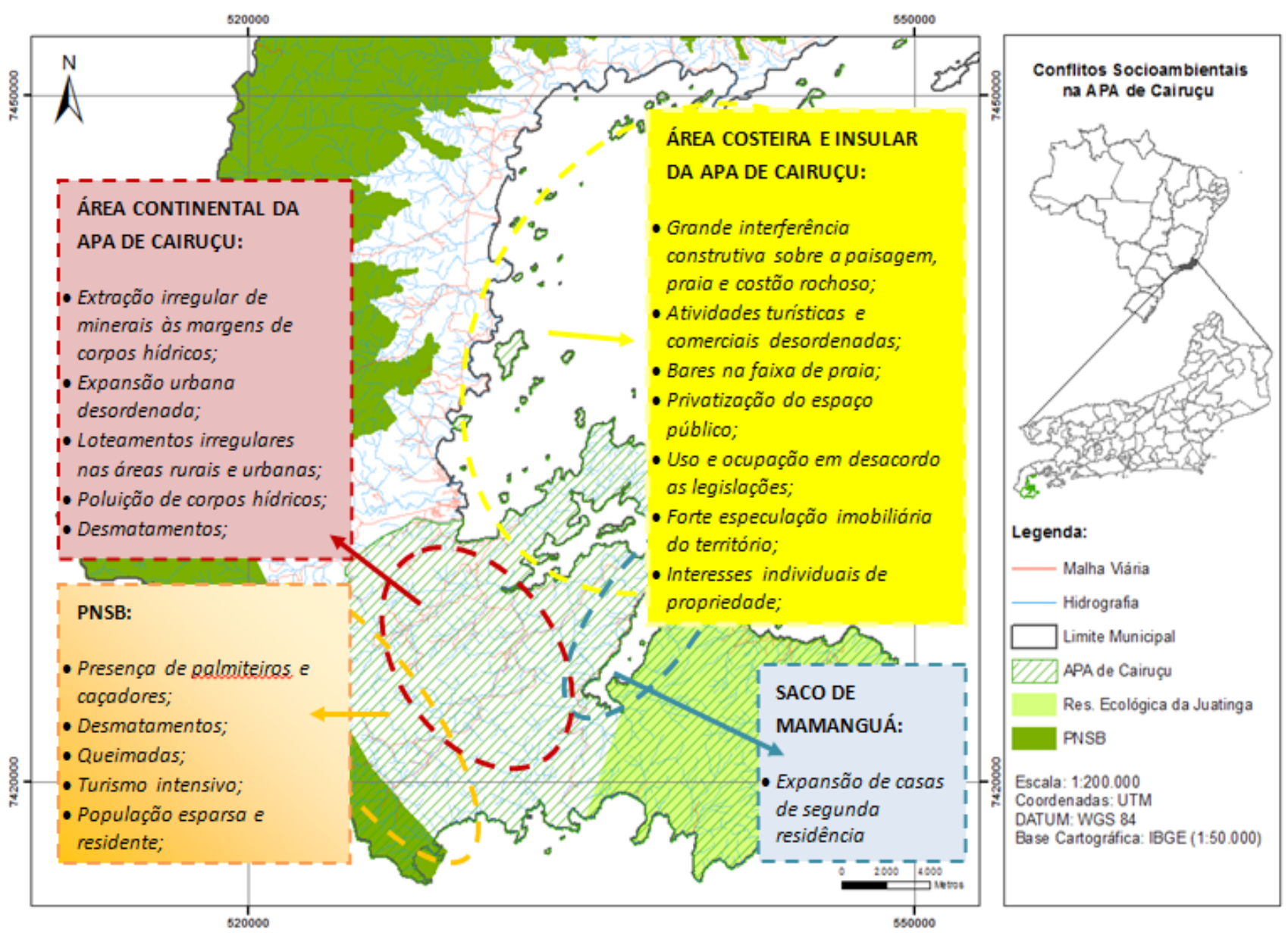

fonte: Carine Fonseca Lopes Fontes e Antônio José Teixeira Guerra, 2013.

\section{Considerações finais}

Por sua extensa dimensão territorial, por estar sobreposta a outras UC, cujos usos são mais restritivos, e por permitir uso intensivo do solo, admitindo atividades variadas, a APA de Cairuçu está sujeita a conflitos. Talvez exatamente pela grande variedade de usos, sua gestão seja um enorme desafio, pois, se não fiscalizada e adequadamente monitorada, pode estar fadada ao descontrole e ao fracasso.

Observam-se na APA inúmeros conflitos, cuja origem está ligada à própria gênese da unidade. Seu decreto de criação impôs antecipadamente restrições de "cima para baixo", sem uma gestão compartilhada e participativa. Igualmente, o Plano de Manejo, que deveria ser o instrumento legítimo de ordenamento do território, como preconiza o Snuc, também cria um zoneamento fundamentado em bases pouco sólidas, com baixa participação popular desde a sua concepção, refletindo-se num regramento parcialmente imposto, que fragiliza sua legitimidade e aceitação. 
Por estabelecer normas jurídicas, o Plano é uma das principais ferramentas de gestão de uma UC e não pode ser encarado como um instrumento burocrático de difícil aceitação. Segundo Vivacqua e Vieira (2005), a existência de regras e normas não garante um padrão de comportamento favorável à resolução de conflitos relativos aos recursos de uso comum. Se elaborado de autoritariamente, tende a agravar as dissidências. Portanto, deve ser objeto de debates e ampla discussão e com o cuidado de não ser concebido de forma arbitrária, articulando-se integrada e harmoniosamente com os demais instrumentos existentes, evitando conflitos de sobreposição e gestão.

No território da APA, a população local não tem plena confiança na administração da unidade, de onde resultam conflitos de gestão entre seus atores, por ações oficiais que se tornam contraditórias e ineficientes. Há conflitos relativos à falta de conhecimento e informação da população, sobretudo no que tange à política do Snuc e a o real objetivo da categoria APA, pois a população ainda tende a associar todas as áreas protegidas com áreas de proteção integral, à falta de participação na gestão da APA, que deve ser incentivada a incluir as lideranças locais no Conselho Gestor da unidade, como fórum autêntico de articulação local, cuja participação deve ser garantida, à falta de fiscalização integrada do território, pois na prática o que se observa são ações isoladas dos diversos órgãos e esferas governamentais em escala pontual, e ao descrédito do poder público, que tem resultado em falta de acordo e parcerias necessárias em favor da conservação.

Não há como ignorar que a gestão de áreas protegidas é essencialmente política, pois a proteção da natureza envolve diversos conflitos de interesses. Segundo Castro Jr., Coutinho e Freitas (2009), a partir do momento em que a criação de áreas protegidas influencia o ordenamento territorial, gera processos conflituosos. Esse ordenamento, porém, é essencial na busca de desenvolvimento com justiça social e conservação ambiental. Assim, é indiscutível o papel do Estado, a quem cabe o dever de conduzir a política de áreas protegidas no país minimizando os conflitos de gestão. Nesse contexto, o Snuc assume vital importância, pois prevê o estreitamento da relação entre o Estado, os cidadãos e o meio ambiente, por meio da criação de mecanismos que ampliem a participação da sociedade na gestão do sistema (Sousa et al., 2011). Além disso, merece destaque o mosaico de unidades de conservação, pois permite repensar e planejar numa escala mais ampla a gestão da unidade como sistema e com a participação integrada de diferentes atores governamentais e não governamentais.

Diante disso e para minimizar os conflitos na gestão da APA, é necessário investir em estratégias mais eficientes para garantir a permanência da diversidade biológica e a sustentabilidade do ecossistema, mas, paralelamente, o fomento a uma gestão democrática e transparente, envolvendo os diversos atores que atuam no território e que dele fazem parte. Tais estratégias devem envolver diálogo, sensibilização e participação, além de monitoramento e fiscalização mais adequados, pois não basta instituir a unidade para dirimir os conflitos em curso. Ao contrário, na prática, essa criação geralmente concorre para acirrá-los. 


\section{Referências}

ACSELRAD, H. As práticas espaciais e o campo dos conflitos ambientais. In: ACSELRAD, H. (Org.). Conflitos ambientais no Brasil. Rio de Janeiro: Relume Dumará/Fundação Heinrich Böll, 2004.

ADAMS, C. As populações caiçaras e o mito do bom selvagem: a necessidade de uma nova abordagem interdisciplinar. Revista de Antropologia, São Paulo, v. 43, n. 1, p. 145-182, 2000.

BENCHIMOL, M. F. Gestão das unidades de conservação marinhas: um estudo de caso da Área de Proteção Ambiental da Baía de Paraty-RJ. Dissertação (Mestrado em Geografia) - Universidade Federal do Rio de Janeiro, Rio de Janeiro, 2007.

BRASIL. Ministério do Meio Ambiente. Instituto Brasileiro do Meio Ambiente e dos Recursos Naturais Renováveis. Diretoria de Extensão e Relações Comunitárias. Plano de Manejo da APA de Cairuçu. Brasilia, DF: FEC/Unicamp, 2005.

Ministério do Meio Ambiente. Instituto Brasileiro do Meio Ambiente e dos Recursos Naturais Renováveis. Diretoria de Extensão e Relações Comunitárias. Plano de Manejo do Parque Nacional da Serra da Bocaina. Brasilia, DF: FEC/Unicamp, 2002.

Lei no 9.985, de 18 de julho de 2000. Institui o Sistema Nacional de Unidades de Conservação da Natureza e dá outras providências. Disponível em: <http://www.planalto. gov.br/ccivil_03/leis/19985.htm>. Acesso em: 13 jan. 2013.

BRETON, Y. A gestão dos recursos de uso comum em Paraty: pesca e patrimônio nacional. In: DIEGUES, A. C. (Org.). Enciclopédia Caiçara. São Paulo: Hucitec/Nupaub. p. 75122, 2005. v. 3: O olhar estrangeiro.

BRITO, D. M. C. Conflitos em unidades de conservação. Pracs - Revista de Humanidades do Curso de Ciências Sociais, Macapá: Unifap, n. 1, p. 1-12, dez. 2008.

BRITO, M. C. W. Unidades de conservação: intenções e resultados. 2. ed. São Paulo: Annablume/Fapesp, 2003.

CASTRO JR., E.; COUTINHO, B. H.; FREITAS, L. E. Gestão da biodiversidade e áreas protegidas. In: GUERRA, A. J. T.; COELHO, M. C. N. (Org.). Unidades de conservação: abordagens e características geográficas. Rio de Janeiro: Bertrand Brasil, 2009. p. 25-65.

DIEGUES, A. C. A mudança como modelo cultural: o caso da cultura caiçara e da urbanização. In: (Org.). Enciclopédia caiçara. São Paulo: Hucitec/Nupaub/CEC/USP, 2004. v. 1: O olhar do pesquisador.

. (Org.). Saberes tradicionais e biodiversidade no Brasil. Brasilia, DF: MMA, 2001.

DIOS, C. B. Aplicabilidade da legislação ambiental na gestão das unidades de conservação: o caso do Parque Nacional da Restinga de Jurubatiba. Dissertação (Mestrado em Geografia) Universidade Federal do Rio de Janeiro, Rio de Janeiro, Rio de Janeiro, 2005. 
IGARA CONSULTORIA EM AQUICULTURA E GESTÃO AMBIENTAL. Definição de categoria de unidade de conservação da natureza para o espaço territorial constituído pela Reserva Ecológica da Juatinga e Área Estadual de Lazer de Paraty Mirim. Rio de Janeiro, 2011. v. 1-7.

LITTLE, P. E. Ecologia política como etnografia: um guia teórico e metodológico. Horizontes Antropológicos, Porto Alegre, v. 12, n. 25, 2006. Disponível em: <http://www.scielo.br/scielo. php?script=sci_arttextEpid=S0104-71832006000100005 > . Acesso em: 19 fev. 2016

MANZINI, E. J. Entrevista semiestruturada: análise de objetivos e de roteiros. In: SEMINÁRIO INTERNACIONAL SOBRE PESQUISA E ESTUDOS QUALITATIVOS: A pesquisa qualitativa em debate, 2004, Bauru. Anais... Bauru: USC, 2004. CD-ROOM. ISBN: 85-98623-01-06.

MAPA. Ministério da Agricultura, Pecuária e Abastecimento. Superintendência do Desenvolvimento da Pesca. Portaria n. 03-N, de 23 de fevereiro de 1987. Diário Oficial da União. Brasilia, DF, 25 fev. 1987. p. 1-3.

PÁDUA, M. T. J. Do Sistema Nacional de Unidades de Conservação. In: MEDEIROS, R.; ARAÚJO, F. F. S. (Org.). Dez anos do Sistema Nacional de Unidades de Conservação da Natureza: lições do passado, realizações presentes e perspectivas para o futuro. Brasilia, DF: MMA, 2011. p. 21-36.

PARATY. Lei Municipal n. 744, de 9 de novembro de 1987. Amplia a APA Municipal da Baía de Paraty e Saco do Mamanguá. Paraty, 1987. p. 1-3.

. Lei n. 685, de 11 de outubro de 1984. Cria a APA Municipal da Baía de Paraty e Saco do Mamanguá. Paraty, 1984. p. 1-4.

RIO DE JANEIRO (Estado). Decreto Estadual n. 26.057, de 14 de março de 2000. Cria o Comitê Estadual da Reserva da Biosfera da Mata Atlântica no Estado do Rio de Janeiro. Disponível em: <http://gov-ri.jusbrasil.com.br/legislacao/230229/decreto-26057-00>. Acesso em: 17 ago. 2014.

SOUSA, N. O. M. et al. Dez anos de história: avanços e desafios do Sistema Nacional de Unidades de Conservação da Natureza. In: MEDEIROS, R.; ARAÚJO, F. F. S. (Org.). Dez anos do Sistema Nacional de Unidades de Conservação da Natureza: lições do passado, realizações presentes e perspectivas para o futuro. Brasilia, DF: MMA, 2011. p. 7-19.

THEODORO, S. H. (Org.). Mediação de conflitos socioambientais. Rio de Janeiro: Garamond, 2005.

VIANNA, L. P. De invisíveis a protagonistas: populações tradicionais e unidades de conservação. São Paulo: Annablume/Fapesp, 2008.

; ADAMS, C.; DIEGUES, A. C. S. Conflitos entre populações humanas em unidades de conservação em Mata Atlântica. Relatório de pesquisa: versão preliminar. São Paulo: NUPAUB-USP, 1994.

VIVACQUA, M.; VIEIRA, P. H. F. Conflitos socioambientais em unidades de conservação. Politica e Sociedade, Florianópolis: UFSC, v. 4, n. 7. p. 139-162, out. 2005. 